\title{
Modeling the Failure Behavior of Self-Piercing Riveting Joints of 6xxx Aluminum Alloy
}

\author{
Florian Hönsch, Josef Domitner, Christof Sommitsch, and Bruno Götzinger
}

\author{
(Submitted August 14, 2019; in revised form March 16, 2020; published online June 23, 2020)
}

\begin{abstract}
Self-piercing riveting (SPR) is a mechanical joining process which is applied for joining similar and dissimilar lightweight materials in modern car body manufacturing. For qualifying SPR joints, cross sections must be investigated with respect to predefined quality features. Thus, numerous tests must be carried out in order to determine the maximum load capacity of SPR joints for different load angles. The growing number of materials used for the body-in-white requires a reliable and time efficient routine for predicting the joining behavior and the load capacity of SPR joints. In this study, the load capacity of three SPR joints was investigated numerically and experimentally using so-called KS2 samples. The results of axisymmetric two-dimensional finite element simulations (Hönsch et al in $J$ Phys Conf Ser 1063:1-6, 2018) are the basis for three-dimensional simulations of the destructive testing procedure. The experimental setup of destructive testing was modeled using the FE software Simufact Forming 15. The numerically determined load capacity was validated with experimental data. Comparing the failure modes and the force-displacement curves revealed good agreement of simulations and experiments. Therefore, the presented simulation is a powerful tool for predicting the behavior of SPR joints under different load cases.
\end{abstract}

\section{Keywords aluminum alloys, KS2 sample, mechanical joining,} numerical simulation, self-piercing riveting (SPR)

\section{Introduction}

According to Papadimitriou et al. (Ref 1), three approaches of lightweight design can be distinguished: (1) reducing the size of vehicles, (2) optimizing the design of vehicles and (3) using lightweight materials. Thus, lightweight design is one key enabler to fulfill today's environmental requirements. Since size and design of new vehicles are mostly predefined by the original equipment manufacturer (OEM), lightweight materials such as advanced- and ultra-high-strength steels (AHSS, UHSS), high-strength aluminum alloys (5xxx, 6xxx, 7xxx) and fiber-reinforced plastics (CFRP, GFRP) are applied increasingly to build the so-called body-in-white (Ref 2). However, the application of dissimilar materials causes various challenges. He et al. (Ref 3) explained that thermal joining of

This article is an invited submission to JMEP selected from presentations at the Symposium "Joining and Related Technologies," belonging to the topic "Processing" at the European Congress and Exhibition on Advanced Materials and Processes (EUROMAT 2019), held September 1-5, 2019, in Stockholm, Sweden, and has been expanded from the original presentation.

Florian Hönsch, Research Group of Tools and Forming, Institute of Materials Science, Joining and Forming, Graz University of Technology, 8010 Graz, Austria; and Magna Steyr Fahrzeugtechnik AG \& Co KG, 8041 Graz, Austria; Josef Domitner and Christof Sommitsch, Research Group of Tools and Forming, Institute of Materials Science, Joining and Forming, Graz University of Technology, 8010 Graz, Austria; and Bruno Götzinger, Magna Steyr Fahrzeugtechnik AG \& Co KG, 8041 Graz, Austria. Contact e-mail: florian.hoensch@student.tugraz.at. lightweight materials is often difficult or even impossible, because of the different physical and chemical properties of the materials to be joined. Thus, mechanical joining processes such as self-piercing riveting (SPR) may solve these problems. In the SPR process, a semi-tubular rivet is pushed into a stack of blanks without needing a predrilled hole. After piercing the upper blank(s), the rivet creates an interlock with the bottom blank without penetrating it. SPR joints are water- and gasproof, and they reveal high static strength and good fatigue performance.

Nowadays, it is common practice to prepare, to investigate and to qualify cross sections of joints by means of optical microscopy (Ref 4). Haque (Ref 5) identified horizontal interlock, height of the rivet head and remaining bottom thickness of the lower blank as crucial quality features. The horizontal interlock influences the mechanical strength distinctly, whereas the height of the rivet head and the remaining bottom thickness are crucial for the corrosion resistance of the joint. Ma et al. (Ref 6) stated that the variety of different stacks and blank thicknesses is challenging for selecting rivets and dies. They investigated the influence of rivet hardness, rivet length, die width and pip height on the riveting result and on the mechanical performance of dissimilar joints of aluminum alloy and mild steel. Based on the experimental results, they identified the volume ratio between the die and the rivet as crucial parameter influencing bottom cracking and mechanical performance of joints. They concluded that experimental testing is very costly, because the virtually endless combinations of different rivet types, blank thicknesses and blank materials require a vast number of samples to be tested. Numerical methods are helpful for investigating in detail the influencing parameters and, therefore, for supporting the design of SPR joints with optimized mechanical properties.

Carandente et al. (Ref 7) investigated SPR using the finite element (FE) software Simufact Forming. In their numerical studies, piercing the upper blank by the rivet was considered by means of eroding mesh elements. Erosion took place when the 
predefined threshold value of the minimum blank thickness was reached. A large threshold value results in a considerable drop of the force when piercing occurs, but this drop almost disappears if the threshold value is rather small. The simulation overestimated the forces when piercing the upper blank; however, the numerical and the experimental curves fit well after piercing. Since thermomechanical properties were used for modeling the blanks, an improved correlation of the experimental and the numerical results was achieved. Huang et al. (Ref 8) used the FE software LS-DYNA for studying residual stresses in dissimilar SPR joints of 6111 aluminum alloy in T4 temper and HSLA340 steel. Failure of the materials was modeled using the maximum shear strain failure criterion. The stresses determined in the numerical simulation correlated well with the experimental data derived from neutron diffraction. The 6111 aluminum alloy blank showed no distinct influence of the strain rate on the flow curves at temperatures below $130{ }^{\circ} \mathrm{C}$, whereas the HSLA340 steel blank showed a significant strain rate sensitivity even at room temperature. Hönsch et al. (Ref 9) found that the high-strength steel used for producing rivets shows distinct strain rate dependency, which must be included in material models used for SPR simulations.

A common approach for determining the load capacity of SPR joints is shear-tension testing. Yan et al. (Ref 10) investigated the shear load capacity of thin-walled steel structures for different configurations of rivets. The influence of rivet number, rivet configuration and blank stacking on the total shear strength and on the failure mechanism of the joints was determined. The main failure mechanism observed was ductile failure based on the pull-out of the rivet. They also recommended a thickness ratio $>1.5$ between bottom blank and top blank to ensure satisfying mechanical properties. Han et al. (Ref 11) investigated the influence of different sample configurations on the shear strength and on the peel strength of multilayer SPR joints. They found that the sample configuration influences both the load capacity and the failure mechanism of these joints. The load angle affects significantly both the maximum force bearable and the energy consumption until failure. Depending on the actual load case, either interlock failure or blank material failure may occur. If the blank fails, the maximum force bearable by the joint can be increased using blank materials of higher strength; however, if interlock failure occurs, the maximum force cannot be increased. Mori et al. (Ref 12) investigated the impact of different blank stacking orders on the cross-tension strength and on the failure mechanism of SPR joints. They modeled the SPR process using the FE software LS-DYNA. Particularly, when using high-strength steels, the stacking order of the blanks was identified as crucial for sufficient joining. If the blank of the highest strength was located in the middle of the stack, large plastic deformation of the rivet was prevented and reliable joining was possible. FE-based optimization of the geometries of both rivet and die improved the joinability. Haque and Durandet (Ref 13) conducted cross-tension and shear-tension tests on dissimilar SPR joints in order to derive an empirical model for predicting the mechanical properties of the joints. The model, which was based on data from the forcedisplacement curve measured during the SPR process, allowed predicting the cross-tension strength within an error range of $10 \%$. Furthermore, a relationship between the shear load capacity and the cross-tension capacity of the joints was determined within an error range of $8 \%$.
Besides using flat blank samples for testing mechanical properties of SPR joints, so-called KS2 samples are utilized. These samples consist of two U-bend blanks which are joined using SPR. Zhang et al. (Ref 14) performed static tests and fatigue tests under both shear load and tensile load. For the static tests flat blank samples, but for the fatigue tests KS2 samples were used. The shear strength increased considerably when using steel blanks of high strength, whereas the increase in tensile strength was only small. They concluded that SPR joints may generally withstand higher shear loads than tensile loads, and that material and thickness of the blank may distinctly influence the strength of the joint. Porcaro et al. (Ref 15 ) investigated mechanical properties of various SPR joints of 6060 aluminum alloy. In the experimental part of the study, the temper, blank thickness, rivet type and die type were varied. $\mathrm{KS} 2$ samples were used to determine the load capacity at angles of $0^{\circ}, 45^{\circ}$ and $90^{\circ}$ to the rivet axis. Furthermore, the peel strength was experimentally determined. In the numerical part of the study, the SPR process was numerically investigated. The results of the $2 \mathrm{D}$ riveting simulation including joint geometry, stresses and strains were mapped to the 3D model of the testing simulation. Both the 2D and the 3D model were built using the LS-DYNA software. Domitner et al. (Ref 16) also investigated SPR joints of $6 \mathrm{xxx}$ aluminum alloy blanks using LS-DYNA, but they utilized the Hypermesh software for building the 2D axisymmetric model of the SPR process. After rotating the results of the SPR simulation (joint geometry, stresses and strains) by $180^{\circ}$ about the center axis of the $2 \mathrm{D}$ model, the results were mapped to $3 \mathrm{D}$ models of the testing processes. Following this approach, cross-tension and shear-tension testing of KS2 samples was successfully modeled and validated with experiments.

In the present study, the failure behavior of three SPR joint configurations exposed to five different load cases is investigated experimentally and numerically. The joint configurations and the numerical SPR model build in Simufact Forming 15 are based on the previous study of Hönsch et al. (Ref 17). As proposed by Hönsch et al. (Ref 9), the flow curves of the highstrength steel rivet are considered as strain rate-dependent. The flow curves of the 6xxx aluminum alloy blanks in T4 temper as well as in heat-treated and annealed condition, which results from the cathodic dip coating (CDC) process, are considered. In order to investigate the load capacity of the SPR joints, KS2 samples according to Hahn et al. (Ref 18) are produced and destructively tested using a tensile testing machine with specially designed fixtures. The KS2 samples consist of two U-bend aluminum alloy blanks which are joined using one steel rivet. The testing process is numerically modeled including the stiffness of the testing setup. Both force-displacement curves captured during testing and failure modes of the KS2 samples are used for validating the numerical results. Considering the strain rate dependency of the steel rivet, thermal annealing of the aluminum blanks, the actual stiffness of the testing setup, and stresses and strains from the SPR simulation improves considerably the numerical predictability of the joint strength.

\section{Simulation studies}

Two-dimensional axisymmetric models of the joining process according to Hönsch et al. (Ref 17) and three-dimensional symmetric models of the destructive testing process were built 
using the FE software Simufact Forming 15. Five load cases with load angles of $0^{\circ}, 30^{\circ}, 45^{\circ}, 60^{\circ}$ and $90^{\circ}$ to the center axis of the rivet were numerically investigated and experimentally tested.

\subsection{Joining model}

The two-dimensional axisymmetric joining model shown in Fig. 1 consisted of rigid components (punch, blankholder and die) and deformable components (rivet and blanks). Tetragonal (quad) elements were used for meshing the deformable components. In the first process step, the blank stack was fixed by applying the predefined blankholder force. In the second process step, the punch pushed the rivet into the blank stack until the predefined displacement was achieved. Because of the high joining forces up to $55 \mathrm{kN}$ (blankholder force + punch force), the elastic deformation of the riveting pliers was considered in the numerical model. To include this deformation in the simulation, a numerical spring acting in z-direction was introduced at the bottom of the die. Due to both the high punch velocity and the good thermal conductivity of aluminum alloys, the temperature increase caused by friction and by material deformation was assumed as negligible for all the simulations. The main process parameters for the joining simulations listed in Table 1 were based on the previous investigations of Hönsch et al. (Ref 17).

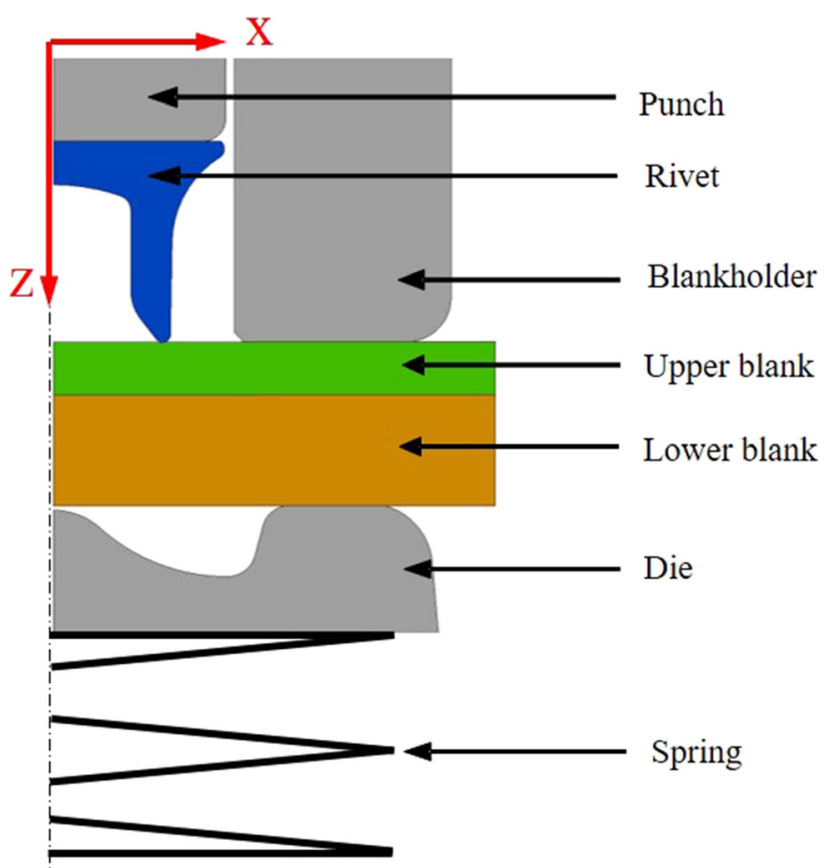

Fig. 1 Model for simulating the riveting process, Hönsch et al. (Ref 17)

Table 1 Main process parameters, Hönsch et al. (Ref 17)
Punch velocity

Blank holder force

Stiffness of the pliers

Process temperature
$100 \mathrm{~mm} / \mathrm{s}$

$10 \mathrm{kN}$

$25 \mathrm{kN} / \mathrm{mm}$

$20{ }^{\circ} \mathrm{C}$
High plastic strains up to $600 \%$ may cause large element distortions in the joining simulations. In order to avoid termination of the calculation caused by distorted or "insideout" elements, frequent remeshing was triggered by a predefined strain change limit. The minimum blank thickness was predefined as damage criterion to enable cutting of the upper blank. Reaching the minimum blank thickness caused geometrical cutting of the upper blank in the subsequent remeshing operation, i.e., elements smaller than the minimum thickness were deleted. The minimum blank thickness was $0.02 \mathrm{~mm}$ for all the joining simulations. A combined friction model consisting of Coulomb's friction and shear friction was applied for all contact faces. The Coulomb's friction coefficients, $\mu$, as well as the shear friction coefficients, $m$, listed in Table 2 were determined by Hönsch et al. (Ref 17) using iterative inverse modeling and validation with experimental data.

\subsection{Testing model}

In order to provide information about the failure behavior of SPR joints for vehicle crash simulations, the load capacity of the joints was investigated for load angles of $0^{\circ}, 30^{\circ}, 45^{\circ}, 60^{\circ}$ and $90^{\circ}$ to the center axis of the rivet. Therefore, besides experimental testing, the five load cases illustrated in Fig. 2 were also modeled in Simufact Forming 15.

The models for the simulation of destructive testing include the moving rigid fixture, the non-moving rigid fixture and the deformable KS2 sample. The three-dimensional model of the KS2 sample consisted of the U-bend upper blank, the U-bend lower blank and the two blank sections with the rivet imported from the two-dimensional joining simulation. All deformable components were meshed using tetrahedral elements. The stresses and strains calculated in the joining simulation were also mapped to the model of the testing process. The stresses and strains induced during the U-bending process of the samples were assumed as negligible. In order to apply the desired load case, the numerical setup was tilted according to the global coordinate system shown in Fig. 2. In Fig. 3, the numerical setup of the testing process is illustrated.

As shown in Fig. 3, the components imported from the last step of the joining simulation were connected to the upper and to the lower blank of the KS2 samples. No relative motion was allowed between the nodes of the blanks derived from the joining simulation and the nodes of the KS2 samples. The velocity $(0.166 \mathrm{~mm} / \mathrm{s})$ and the displacement $(10 \mathrm{~mm})$ defined the movement of the upper fixture in z-direction. However, lateral forces occurring in the experiment caused noticeable elastic deformation of the fixtures in x-direction, which had to be considered in the numerical studies. For this reason, the lateral stiffness of the fixtures was taken into account for all load cases where lateral forces occurred, but not for the $0^{\circ}$ load case. Hence, a numerical spring with an equivalent stiffness representing the overall stiffness of the clamping system was assigned to the lower fixture for each load case. The stiffness of the numerical spring was determined by tracking the movement of the fixtures during the experiment. The equivalent stiffnesses are listed in Table 3.

The friction coefficients used in the simulation of destructive testing were identical with the coefficients used in the joining simulations, as listed in Table 2. Friction- and forming-related increase in temperature was neglected, because the load was applied quasi-static. 
Table 2 Friction coefficients, Hönsch et al. (Ref 17)

\begin{tabular}{lccccc}
\hline Friction coeff. & Blank/ blank & Blank/ rivet & Blank/die & Blank/b. holder & Punch/ rivet \\
\hline$\mu$ & 0.2 & 0.1 & 0.3 & 0.2 & 0.2 \\
$m$ & 0.4 & 0.3 & 0.45 & 0.4 & 0.5 \\
\hline
\end{tabular}

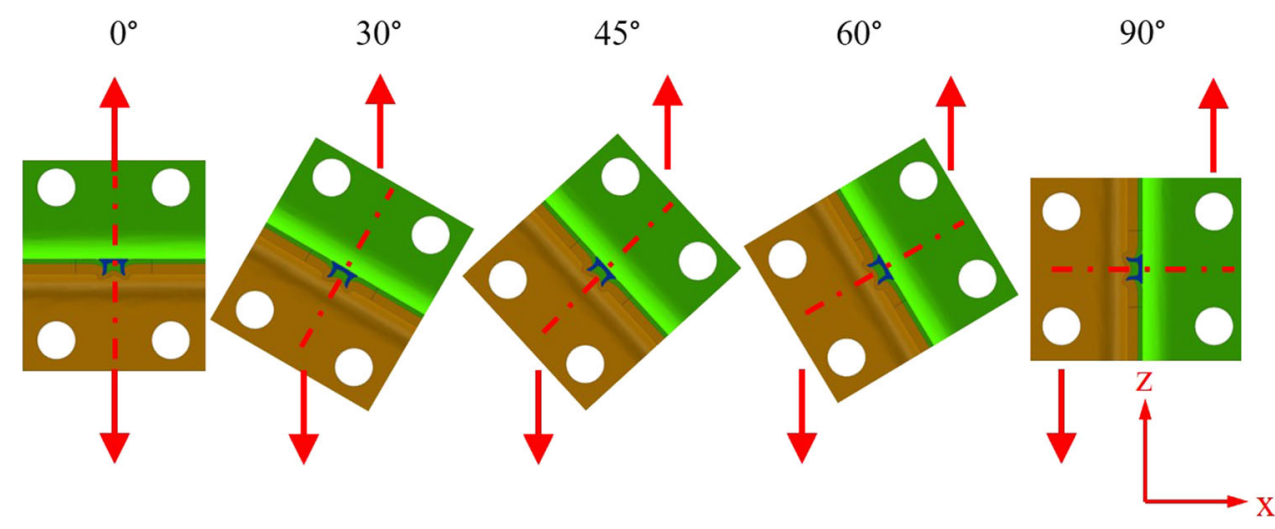

Fig. 2 Load cases for testing the KS2 samples
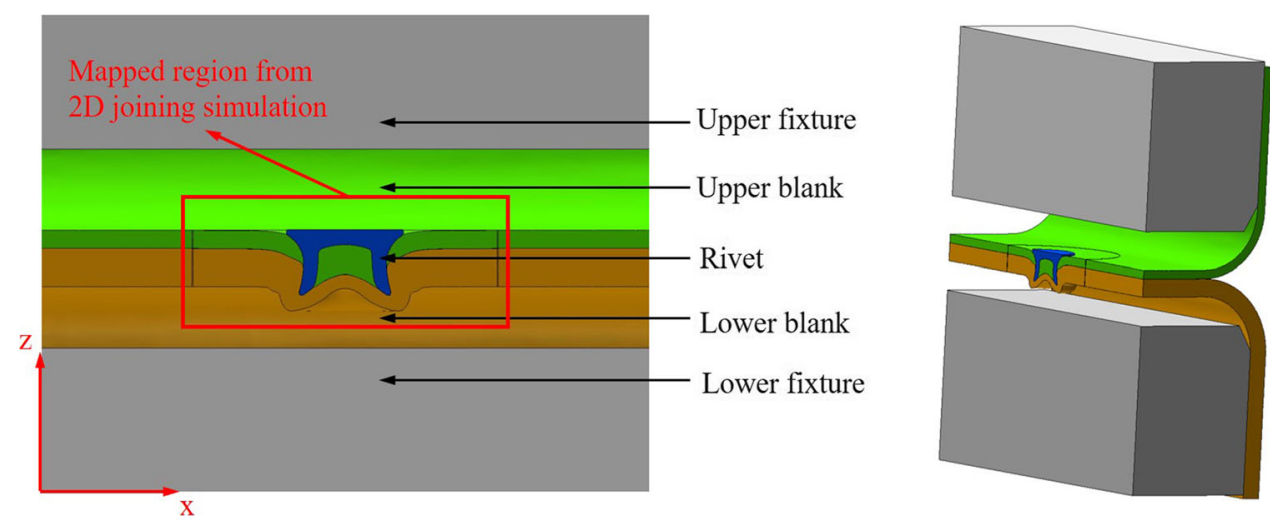

Fig. 3 Model for simulating destructive testing of the KS2 samples

Table 3 Equivalent stiffness values of the fixtures

\begin{tabular}{lccccc}
\hline Load case & $\mathbf{0}^{\circ}$ & $\mathbf{3 0}^{\circ}$ & $\mathbf{4 5}^{\circ}$ & $\mathbf{6 0}^{\circ}$ & $\mathbf{9 0}^{\circ}$ \\
\hline Equivalent stiffness, N/mm & $\ldots$ & 90 & 120 & 150 & 500 \\
\hline
\end{tabular}

\subsection{Material}

Many structural parts and outer panels for body-in-white applications are made from 6xxx aluminum alloy blanks, which are formed and joined in T4 temper condition. After assembling, the body-in-white is exposed to temperatures up to $200{ }^{\circ} \mathrm{C}$ during the cathodic dip coating (CDC) process. Due to the aging behavior of $6 \mathrm{xxx}$ aluminum alloys, the material properties of the blanks change significantly during this heat treatment. In order to obtain the flow curves for both T4 temper and heat-treated (HT) condition, quasi-static tensile testing was conducted according to DIN EN ISO 6892-1. The experimentally obtained flow curves were extrapolated to true strains of $\varphi>0.2$ using the extrapolation of Hockett and Sherby (Ref 19) which was extended with a linear term:
Table 4 Extrapolation parameters for the flow curves

\begin{tabular}{lrrrrr}
\hline & $\boldsymbol{A}$ & $\boldsymbol{B}$ & $\boldsymbol{C}$ & $\boldsymbol{m}$ & $\boldsymbol{n}$ \\
\hline Blank T4 & 125 & 340 & 20 & 6.5 & 0.82 \\
Blank HT & 188 & 352 & 5 & 6.8 & 0.84 \\
Rivet & 1520 & 1680 & 10 & 30 & 0.76 \\
\hline
\end{tabular}

$\sigma_{\mathrm{T}}=B-(B-A) \mathrm{e}^{-m \varphi^{n}}+C \cdot \varphi$

In Eq 1, $A$ defines the flow stress at true strain of zero. $B$ is the saturation flow stress of the Hockett-Sherby law. Parameters $m$ and $n$ define the slope and the shape of the curve, respectively. $C$ defines the slope of the flow curve at high strains to consider strain hardening of the aluminum alloy. All parameters used for extrapolating the flow curves are listed in Table 4.

For the aluminum alloy investigated, the flow curves for plastic strains up to approx. $20 \%$ were obtained using tensile testing. Note that the stress-strain curve of the $6 \mathrm{xxx}$ aluminum 
alloy used in the destructive testing simulation was determined after the CDC process in the heat-treated condition. Since microstructural evolution due to the CDC process was neglected in the present model, the change of the residual stresses inside the blanks during heat treatment was not considered. The flow curves calculated using $\mathrm{Eq} 1$ for the blanks in both the T4 temper and the heat-treated (HT) conditions are displayed in Fig. 4.

Since rivets consist of high-strength manganese-boron steel, their mechanical properties are not noticeably influenced by the comparatively low temperature of the CDC process. However, the hardening behavior of the steel is greatly influenced by the strain rate. For investigating the strain rate dependency, highspeed compression tests on hollow-cylindrical samples extracted from rivets were carried out using a Gleeble 3800 testing machine. Vaseline and Teflon foil were used for reducing friction between the rivet and the jaws of the machine. Based on the measured force-displacement curves, flow curves of the rivet material were created. Numerical simulations of the compression tests were conducted, and the flow curves were optimized by iterative inverse modeling. Details about the compression tests are described in the study of Hönsch et al. (Ref 9). The flow curves of the manganese-boron steel at room temperature are displayed in Fig. 5. In the present model, the temperature influence on the flow curves was not considered for the same reasons as for the blank material.

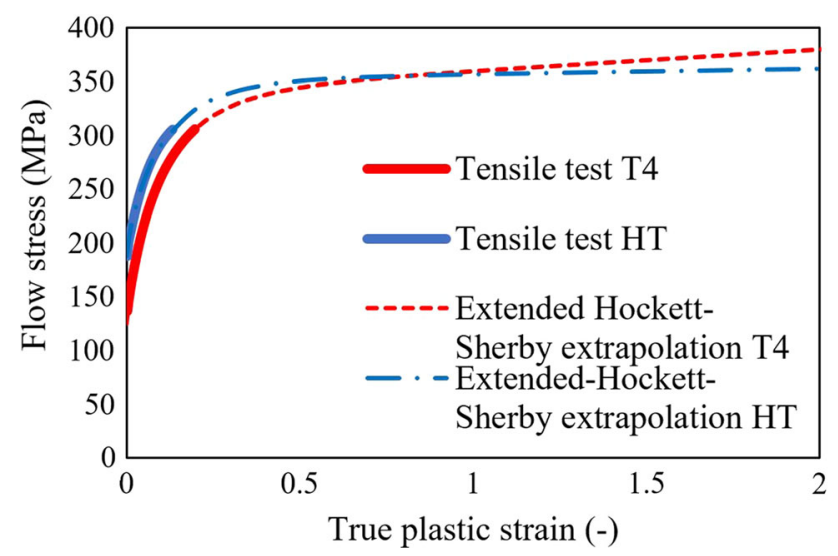

Fig. 4 Flow curves of the aluminum alloy blank for conditions HT and T4, Hönsch et al. (Ref 17)
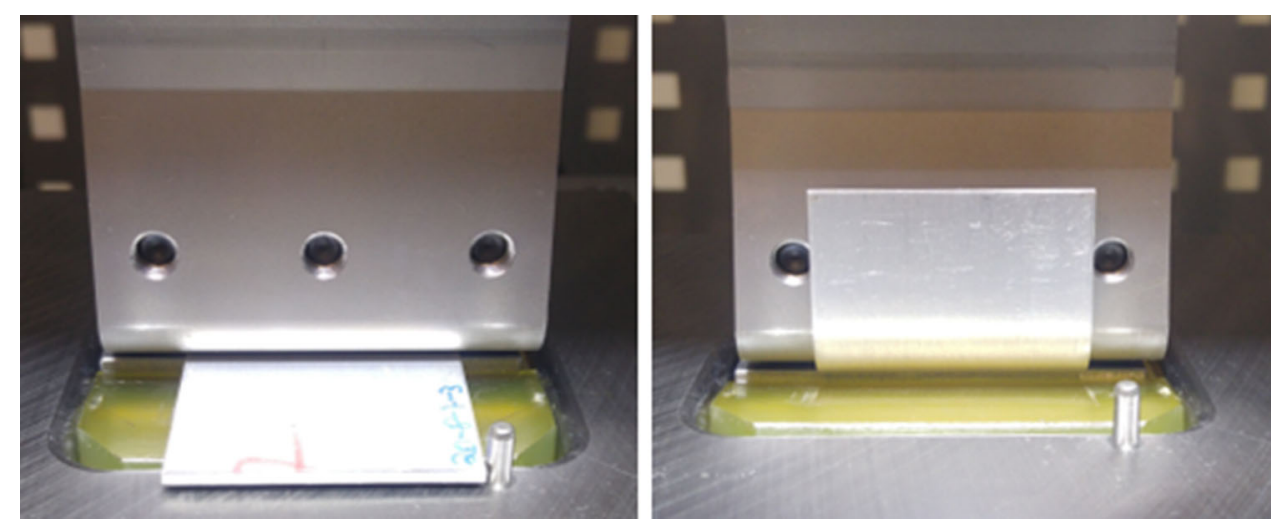

Fig. 6 U-bending of sample halves for KS2 samples

\section{Experimental studies}

Three combinations of 1.2 and $2.5-\mathrm{mm}$ thick $6 \mathrm{xxx}$ aluminum alloy blanks in T4 temper condition were joined in the following three blank combinations: (1) $1.2 \mathrm{~mm} / 1.2 \mathrm{~mm}$, (2) $1.2 \mathrm{~mm} / 2.5 \mathrm{~mm}$ and (3) $2.5 \mathrm{~mm} / 2.5 \mathrm{~mm}$. For combinations

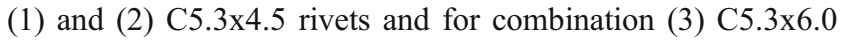
rivets were used; however, the identical die was used for each of these three combinations. During the riveting process, the process data were captured directly at the pliers. The raw data were then exported for calculating force-displacement curves of the punch. After riveting, the joints were cut, embedded, ground and polished for analyzing the characteristic dimensions of the joints, e.g., horizontal interlock, rivet head height and residual bottom thickness. The cross sections were investigated using a Keyence VHX 6000 digital microscope.

All destructive tests were conducted using KS2 samples as displayed in Fig. 7(a). In the first production step of the KS2 samples, flat blanks were bent to U-shaped sample halves. An adjustable steel punch and an elastomer die were used for the bending process. The benefits of bending using elastomers are the good surface quality and the process stability. Screws for widening and narrowing the punch allowed adjusting the distance between the shanks of the sample halves. This enables bending of different materials and blank thicknesses using only a single punch. The bending operation is illustrated in Fig. 6.

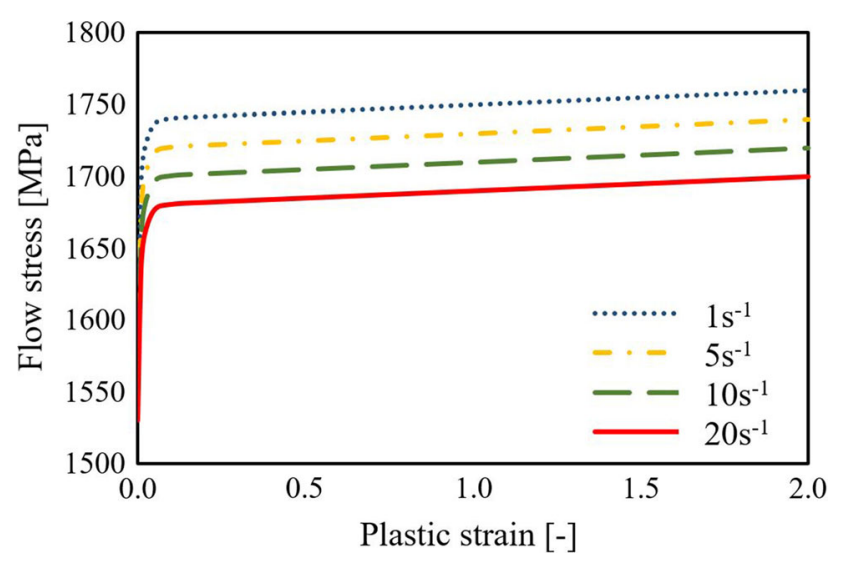

Fig. 5 Strain rate-dependent flow curves of the rivet material at room temperature, Hönsch et al. (Ref 9) 
In the second production step, two precision holes were drilled into the sample halves in order to connect the KS2 sample to the fixtures for destructive testing. A special drilling tool was designed and manufactured for this purpose. Finally, for obtaining the KS2 sample, two sample halves were clamped and joined using a positioning device. Different fixtures were used for testing the samples according to the five load cases. Each KS2 sample was connected to the fixtures using dowel screws and spacers. Three samples were manufactured and tested for each load case or joint configuration, respectively. Exemplarily, the setups of the cross-tension test and of the shear-tension test are displayed in Fig. 7(b) and (c).

During the tests, the tensile force was measured using the load cell of a Zwick Z250 tensile testing machine, and the displacement was measured using a Zwick LaserXtens system. Two typical failure modes were obtained from the cross-tension experiments: tearing the rivet out of the bottom blank, Fig. 8(a), or pulling the upper blank over the rivet head, Fig. 8(b). In all other load cases, the rivet was rotated out of the lower blank. Figure 8(c) shows the typical failure mode observed for the shear-tension experiments.

\section{Results and discussion}

The predictive quality of the joint testing simulation depends to a great extent on the input data mapped from the joining simulations. For this reason, validating the results of the joining simulations using polished cross sections of the joints and forcedisplacement curves of the SPR process is essential. Figure 9 compares cross sections and force-displacement curves obtained from both the riveting experiments and the riveting simulations of the three joint configurations investigated. The red contour lines in the illustrations represent the numerical results, which are compared to cross-sectional images. Three phases can be distinguished when comparing the numerical and the experimental force-displacement curves: (1) gradually increasing force while penetrating the upper blank, (2) changing slope of the force-displacement curve due to separation of the upper blank, (3) rapidly increasing force while penetrating the lower blank and forming the interlock. One can observe that the simulation slightly overestimates the force in phase (1). This overestimation can have multiple reasons, e.g., fracturing of the material, changing friction conditions or unexpected hardening behavior of the aluminum alloy. However, the force-displacement curves in phase (3) including the maximum forces are predicted well in
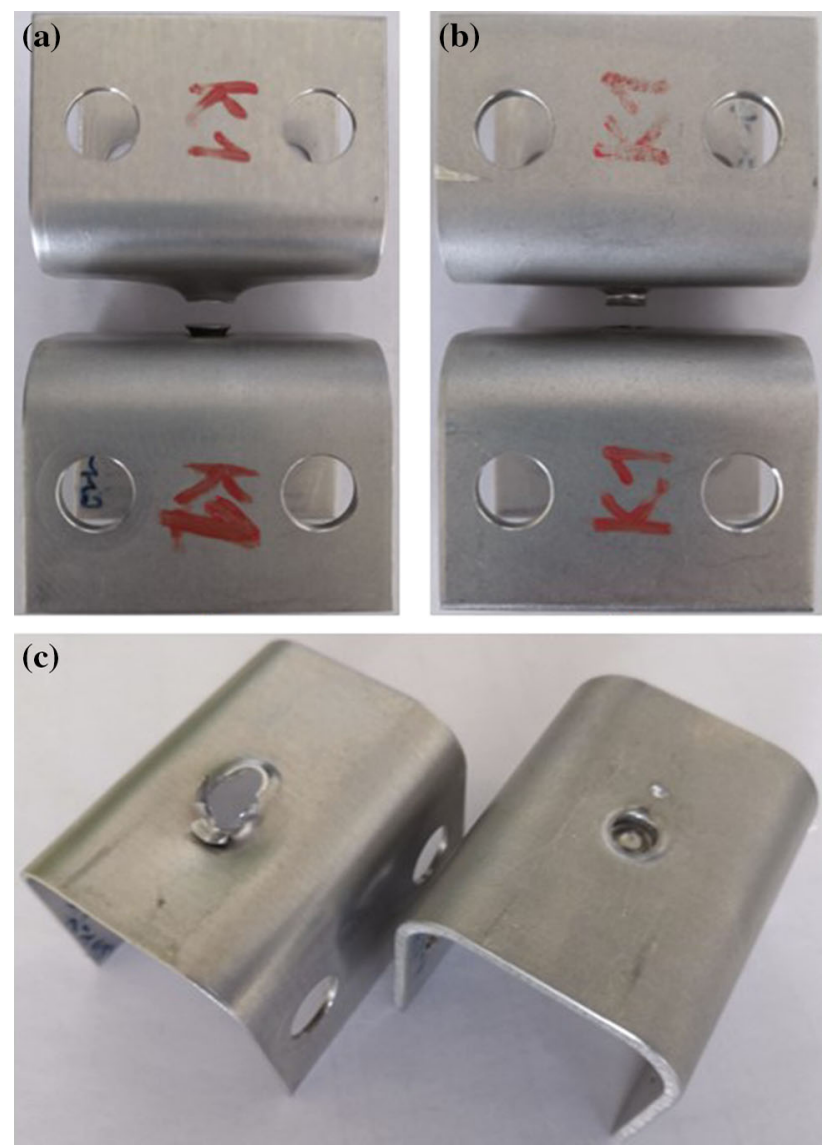

Fig. 8 Failure modes occurring in destructive testing of KS2 samples of different blank combinations: (a) cross-tension sample of $1.2 \mathrm{~mm} / 2.5 \mathrm{~mm}$, (b) cross-tension sample of $2.5 \mathrm{~mm} / 2.5 \mathrm{~mm}$, and (c) shear-tension sample $1.2 \mathrm{~mm} / 2.5 \mathrm{~mm}$
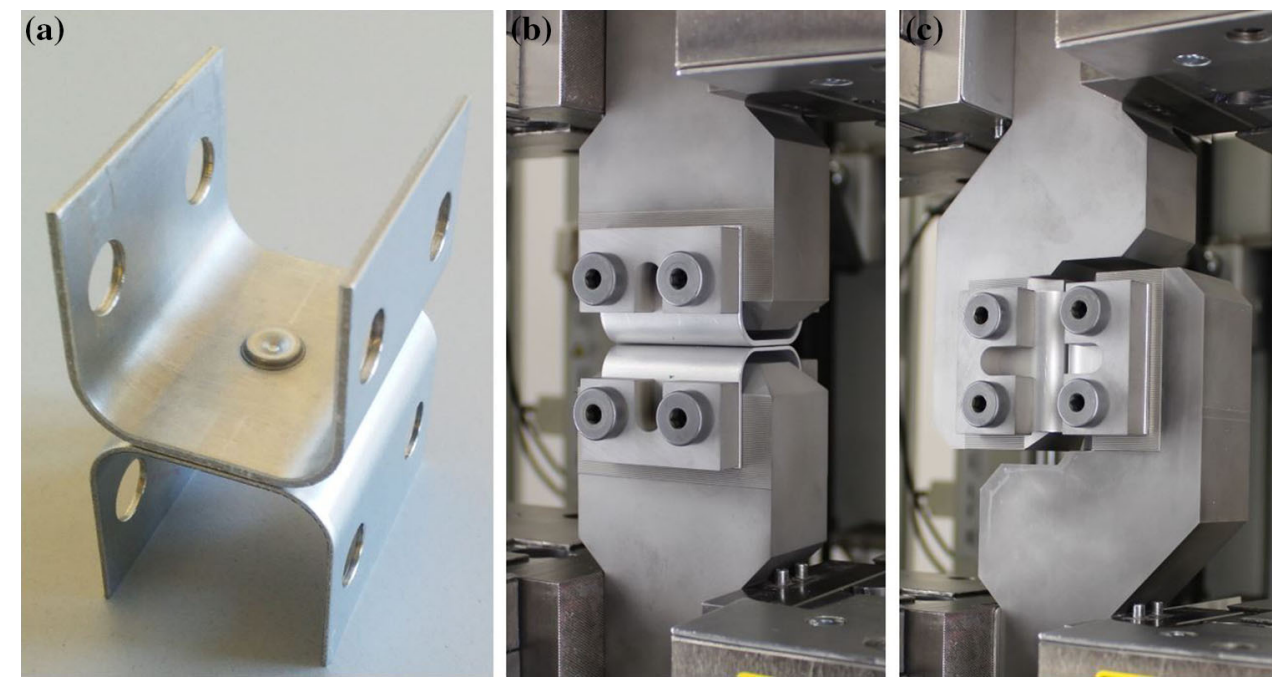

Fig. 7 (a) KS2 sample and setups of (b) cross-tension test and (c) shear-tension test 


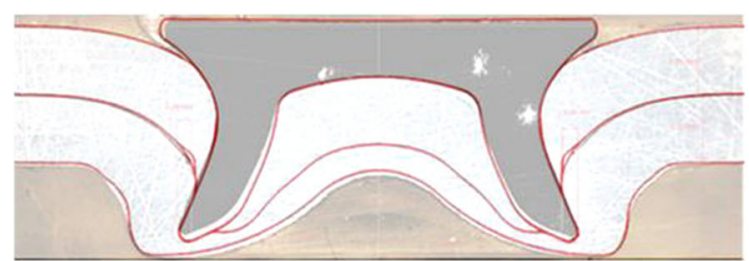

(a)

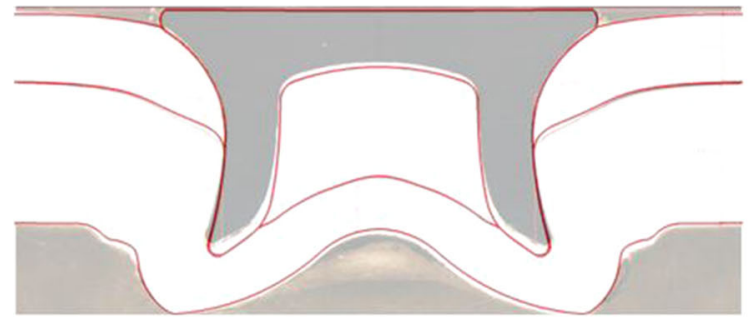

(b)

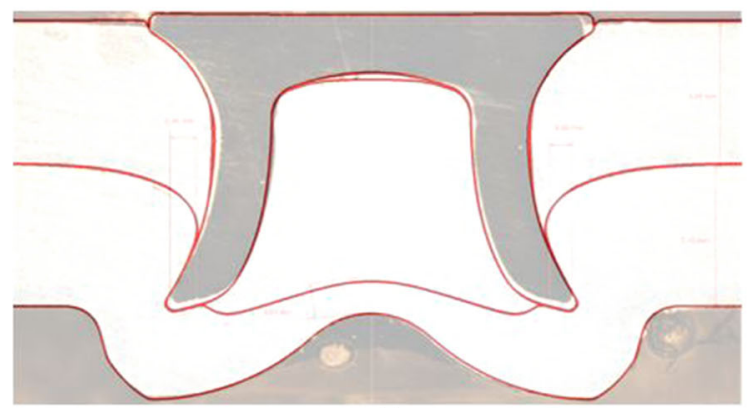

(c)
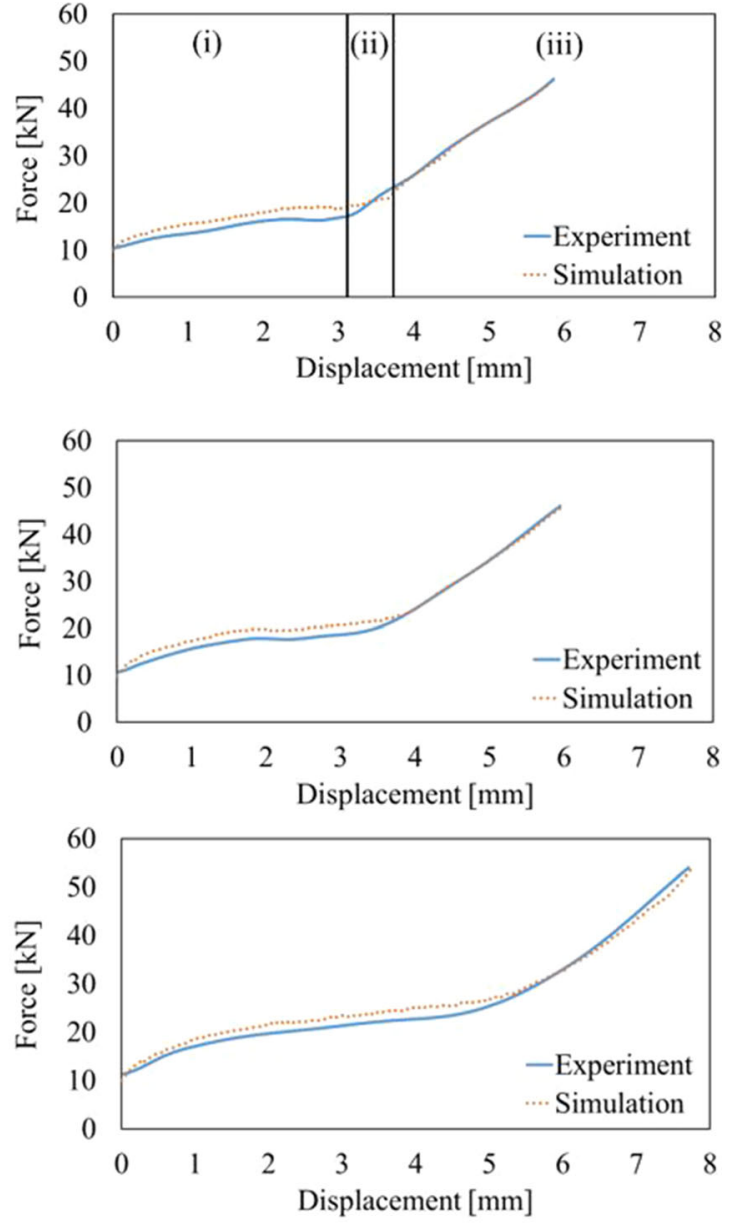

Fig. 9 Comparison between experimental and numerical cross sections and force-displacement curves for three different blank combinations: (a) $1.2 \mathrm{~mm} / 1.2 \mathrm{~mm}$, (b) $1.2 \mathrm{~mm} / 2.5 \mathrm{~mm}$, (c) $2.5 \mathrm{~mm} / 2.5 \mathrm{~mm}$

the simulations. With increasing stack thickness, both the force level and the displacement for achieving the required interlock increase. Since the deviations between the actual and the numerical results were obviously very small, the results of the joining simulations are (c) appropriate as input for the subsequent joint testing simulations.

The force-displacement curves determined in the destructive tests were compared with the curves calculated in the testing simulations. Furthermore, the failure mode observed in the experiment was taken into account for qualitative validation. Figure 10 (right column) shows the force-displacement curves of the testing experiments and of the testing simulation exemplarily for the $1.2 \mathrm{~mm} / 1.2 \mathrm{~mm}$ blank combination. It was observed that the force decreases to zero only for the crosstension test $\left(0^{\circ}\right.$ load case $)$. In all other load cases, the force does not decrease to zero, because the rivet is captured between the blanks after rotating out of the lower blank. Since crack initiation or propagation was neglected in the simulation of destructive testing, the numerical model only approximates the behavior of the components after reaching the maximum force, i.e., after crack initiation. Due to the high element distortions and since the rivet is captured between the blanks, the calculation terminated before reaching the final displacement of $10 \mathrm{~mm}$ as in the experiments. Deviations in the shape of the force-displacement curves and the maximum force levels can have multiple reasons such as insufficient material modeling, non-constant friction parameters, missing crack initiation or nonlinear stiffness of the clamping system. Nevertheless, the maximum force calculated in the simulations was predicted within a deviation of less than $\pm 10 \%$ compared to the experiment. The failure modes occurring in the experiment were also obtained in the simulations.

Table 5 compares the maximum forces reached in the destructive testing simulations and in the testing experiments. For the $1.2 \mathrm{~mm} / 1.2 \mathrm{~mm}$ joints, the maximum force bearable by the joint was underestimated in the simulation in most cases excluding the shear-tension case. The smallest deviations were obtained for the $2.5 \mathrm{~mm} / 2.5 \mathrm{~mm}$ joints, although the maximum shear force was slightly overestimated in the simulation. The largest deviation between experiment and simulations was obtained for the $1.2 \mathrm{~mm} / 2.5 \mathrm{~mm}$ joints, where the shear-tension force showed the greatest deviation for all the joints. Two main factors contributed to the deviations between experiment and simulation: Firstly, the interlock had major influence on the failure behavior of the joints. Small deviations of the interlock obtained from the joining simulation distinctly influence the force-displacement curve determined in the testing simulation. In particular, the maximum force bearable by the joint depends to a great extent on the spreading behavior of the rivet and, therefore, on the interlock achieved. Secondly, material failure due to crack formation was not included in the testing simulation. Future investigations should examine this topic in depth. 

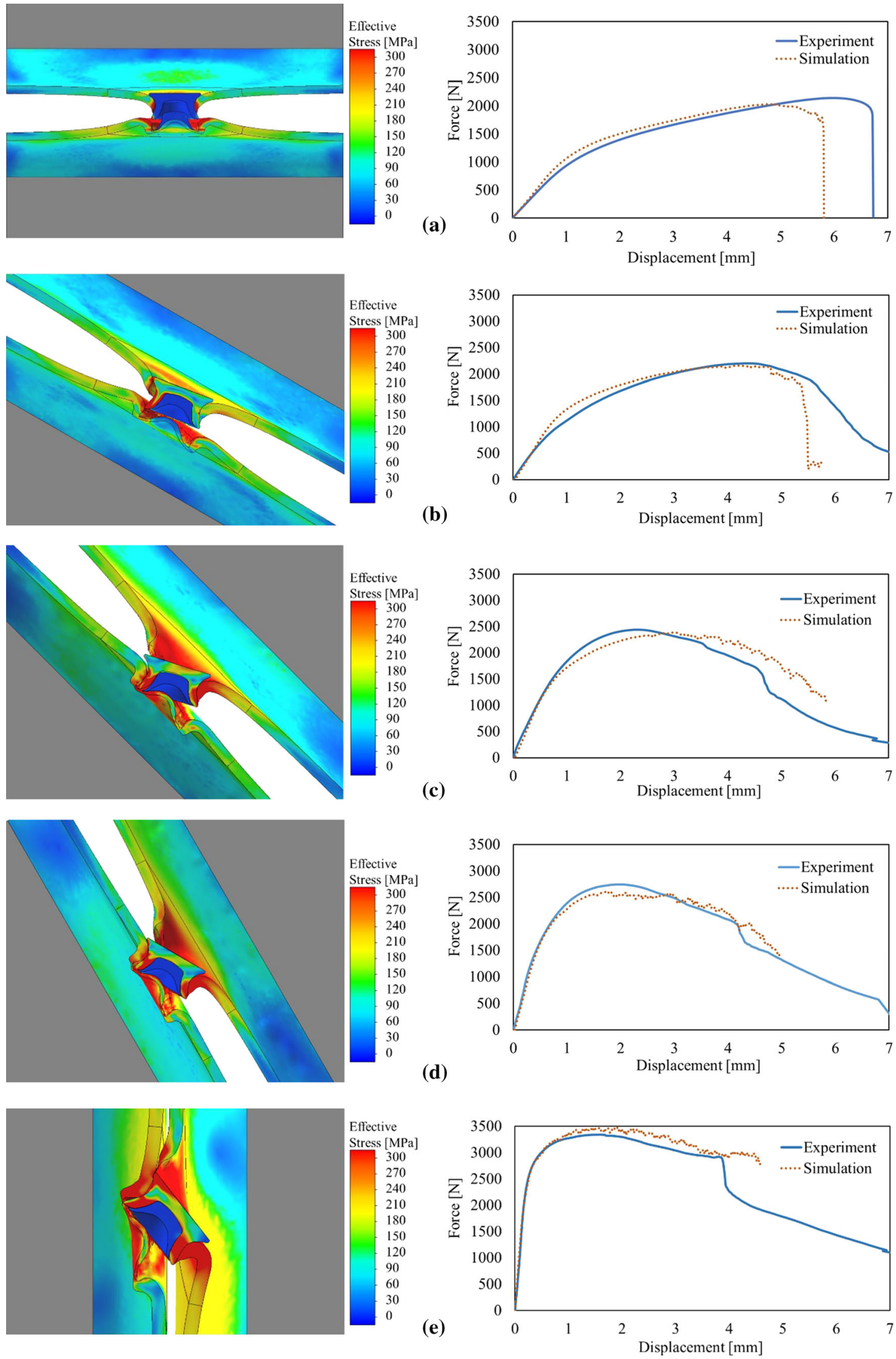

Fig. 10 Effective stress calculated in the simulation (left column) and comparison between force-displacement curves from experiments and simulation (right column) for five load cases (a) $0^{\circ}$, (b) $30^{\circ}$, (c) $45^{\circ}$, (d) $60^{\circ}$, (e) $90^{\circ}$ 
Table 5 Comparison of the maximum forces of experiments and simulations

\begin{tabular}{|c|c|c|c|c|}
\hline Blank combination & Load case, $^{\circ}$ & Max. force (simulation), $\mathbf{N}$ & Max. force (experiment), $\mathbf{N}$ & Deviation, $\%$ \\
\hline \multirow[t]{5}{*}{$1.2 \mathrm{~mm} / 1.2 \mathrm{~mm}$} & 0 & 1948 & 2095 & -7.0 \\
\hline & 30 & 2161 & 2203 & -1.9 \\
\hline & 45 & 2391 & 2438 & -1.9 \\
\hline & 60 & 2606 & 2745 & -5.1 \\
\hline & 90 & 3447 & 3339 & 3.2 \\
\hline \multirow[t]{5}{*}{$1.2 \mathrm{~mm} / 2.5 \mathrm{~mm}$} & 0 & 2587 & 2689 & -3.8 \\
\hline & 30 & 2469 & 2290 & 7.8 \\
\hline & 45 & 2463 & 2396 & 2.8 \\
\hline & 60 & 2674 & 2654 & 0.8 \\
\hline & 90 & 4227 & 3850 & 9.8 \\
\hline \multirow[t]{5}{*}{$2.5 \mathrm{~mm} / 2.5 \mathrm{~mm}$} & 0 & 4499 & 4452 & 1.1 \\
\hline & 30 & 4897 & 4757 & 2.9 \\
\hline & 45 & 5662 & 5663 & 0.0 \\
\hline & 60 & 6045 & 6036 & 0.1 \\
\hline & 90 & 8341 & 7788 & 7.1 \\
\hline
\end{tabular}

\section{Summary and outlook}

In this study, processes for joining and destructive testing of three SPR joints were numerically modeled and experimentally validated. Significant improvement of the models for joining and testing was achieved by taking into account the strain rate dependency of the steel rivet, thermal annealing of the aluminum blanks during the CDC process, and the actual stiffnesses of both the riveting and the testing setups. The stresses and strains which were calculated using the 2D model of the joining process served as initial state in the 3D model of the testing process. The maximum force bearable by the joint was determined for five different load cases, i.e., the tension force was applied at load angles of $0^{\circ}, 30^{\circ}, 45^{\circ}, 60^{\circ}$ and $90^{\circ}$ to the rivet axis. For each load case and joint configuration investigated, the maximum force was predicted within the range of $\pm 10 \%$ in comparison with the experiment. The forcedisplacement curves calculated in the simulations of both riveting and destructive testing agreed well with the forcedisplacement curves measured in the experiments. Furthermore, good agreement of the cross sections of the joints was achieved in experiments and simulations.

Large deformations associated with crack formation in the vicinity of the joint were observed in destructive testing of KS2 samples. Since modeling of crack formation was beyond the scope of this work, it was not included in the present model. In order to improve the predictive quality of the model, however, cracking mechanisms, a velocity- and temperature-dependent friction model, as well as temperature- and strain ratedependent material data for the blank material should be included.

\section{Acknowledgments}

Open access funding provided by Graz University of Technology. The authors gratefully thank Magna Steyr Fahrzeugtechnik AG \& Co KG, Austria, for funding this study and for supporting the experimental tests. The authors also like to thank STANLEY ${ }^{\circledR}$ Engineered Fastening, Tucker GmbH, Germany, for their support. Special thanks go to all employees of the Institute of Materials Science, Joining and Forming at Graz University of Technology involved in the project.

\section{Open Access}

This article is licensed under a Creative Commons Attribution 4.0 International License, which permits use, sharing, adaptation, distribution and reproduction in any medium or format, as long as you give appropriate credit to the original author(s) and the source, provide a link to the Creative Commons licence, and indicate if changes were made. The images or other third party material in this article are included in the article's Creative Commons licence, unless indicated otherwise in a credit line to the material. If material is not included in the article's Creative Commons licence and your intended use is not permitted by statutory regulation or exceeds the permitted use, you will need to obtain permission directly from the copyright holder. To view a copy of this licence, visit http://creativecommons.org/licenses/by/4.0/.

\section{References}

1. I. Papadimitriou, P. Efthymiadis, H.R. Kotadia, I.R. Sohn, and S. Sridhar, Joining TWIP to TWIP and TWIP to Aluminium: A Comparative Study Between Joining Processes, Joint Properties and Mechanical Performance, J. Manuf. Process., 2017, 30, p 195-207

2. G. Meschut, V. Janzen, and T. Olfermann, Innovative and Highly Productive Joining Technologies for Multi-Material Lightweight Car Body Structures, J. Mater. Eng. Perform., 2014, 23, p 1515-1523

3. X. He, I. Pearson, and K. Young, Self-pierce Riveting for Sheet Materials: State of the Art, J. Mater. Process. Technol., 2008, 199, p 27-36

4. D. Li, A. Chrysanthou, I. Patel, and G. Williams, Self-piercing Riveting-A Review, Int. J. Adv. Manuf. Technol., 2017, 92, p 17771824

5. R. Haque, Quality of Self-piercing Riveting (SPR) Joints from CrossSectional Perspective: A Review, Arch. Civ. Mech. Eng., 2018, 18, p 83-93

6. Y. Ma, M. Lou, Y. Li, and Z. Lin, Effect of Rivet and Die on Selfpiercing Rivetability of AA6061-T6 and Mild Steel CR4 of Different Gauges, J. Mater. Process. Technol., 2018, 251, p 282-294

7. M. Carandente, R.J. Dashwood, I.G. Masters, and L. Han, Improvements in Numerical Simulation of the SPR Process Using a Thermomechanical Finite Element Analysis, J. Mater. Process. Technol., 2016, 236, p 148-161

8. L. Huang, J.F.C. Moraes, D. Sediako, J.B. Jordon, H. Guo, and X. Su, Finite-Element and Residual Stress Analysis of Self-Pierce Riveting in Dissimilar Metal Sheets, J. Manuf. Sci. Eng., 2017, 139, p 1-11

9. F. Hönsch, J. Domitner, and C. Sommitsch, Deformation Behavior of High-Strength Steel Rivets for Self-piercing Riveting Applications, AIP Conf. Proc., 2019, 2019, p 1-6 
10. W. Yan, Z. Xie, C. Yu, L. Song, and H. He, Experimental Investigation and Design Method for the Shear Strength of Self-piercing Rivet Connections in Thin-Walled Steel Structures, J. Constr. Steel Res., 2017, 133, p 231-240

11. L. Han, A. Chrysanthou, and K.W. Young, Mechanical Behaviour of Self-piercing Riveted Multi-layer Joints Under Different Specimen Configurations, Mater. Des., 2007, 28, p 2024-2033

12. K. Mori, Y. Abe, and T. Kato, Self-pierce Riveting of Multiple Steel and Aluminium Alloy Sheets, J. Mater. Process. Technol., 2014, 214, p 2002-2008

13. R. Haque and Y. Durandet, Strength Prediction of Self-pierce Riveted Joint in Cross-Tension and Lap-Shear, Mater. Des., 2016, 108, p 666678

14. C. Zhang, R. Gou, M. Yu, Y. Zhang, Y. Qiao, and S. Fang, Mechanical and Fatigue Properties of Self-piercing Riveted Joints in High-Strength Steel and Aluminium Alloy, J. Iron. Steel Res. Int., 2017, 24, p 214 221

15. R. Porcaro, A.G. Hanssen, M. Langseth, and A. Aalberg, The Behaviour of a Self-piercing Riveted Connection Under Quasi- static Loading Conditions, Int. J. Solids Struct., 2006, 43, p 51105131

16. J. Domitner, C. Woltsche, F. Hönsch, C. Sommitsch, Numerical Study on Destructive Testing of Self-piercing Rivet Joints, in Proceedings of the International Conference on Experimental Solid Mechanics, Tehran (2018)

17. F. Hönsch, J. Domitner, C. Sommitsch, B. Götzinger, and M. Kölz, Numerical Simulation and Experimental Validation of Self-piercing Riveting (SPR) of 6xxx Aluminium Alloys for Automotive Applications, J. Phys: Conf. Ser., 2018, 1063, p 1-6

18. O. Hahn, J.R. Kurzok, and M. Oeter, Prüfvorschrift für Die LWF KS2Probe, Paderborn, Pohlweg, 1999

19. J.E. Hockett and O.D. Sherby, Large Strain Deformation of Polycrystalline Metals at Low Homologous Temperatures, J. Mech. Phys. Solids, 1975, 23, p 87-98

Publisher's Note Springer Nature remains neutral with regard to jurisdictional claims in published maps and institutional affiliations. 